\title{
Is E-conferencing a useful communication tool in education and could it be used to promote health and wellbeing?
}

\author{
N. Fordyce ${ }^{1}$, C. Munro ${ }^{1}$, E. Hepburn ${ }^{1}$, S. Ramnarine ${ }^{2}$, J. Mcnulty ${ }^{1}$, K. Cheng ${ }^{1}$, S. Brown ${ }^{1}$, D. Keith ${ }^{1}$, \\ D. Jones ${ }^{3}$ and M. R. Ritchie ${ }^{1,4}$ \\ ${ }^{1}$ Arbroath High School, DD11 3EN, ${ }^{2}$ University of Edinburgh, EH16 4SA, ${ }^{3}$ University of Dundee, DD1 $4 E H$ and ${ }^{4}$ Edinburgh \\ Napier University, EH14 1DJ
}

Diet and its role in disease prevention has been well documented ${ }^{(1)}$. As a consequence, there are numerous government-sponsored initiatives aimed at improving the nutritional status of children ${ }^{(2)}$ including the introduction of the theme of Health and Wellbeing as part of the new Curriculum for Excellence $(\mathrm{CfE})^{(3)}$ currently being introduced in Scottish schools.

E-conferencing is a method of communication presently being developed in Scotland with a view to providing greater opportunities for enhanced communication between schools and outside agencies. The aim of this study was to evaluate to what extent teaching staff felt e-conferencing would provide enhanced opportunities for learning in schools, in particular with the development of Health and Wellbeing within the CfE. The current study was undertaken by pupils in Angus completing a Scottish Baccalaureate, where development of questionnaires and evaluation of responses formed part of their Interdisciplinary Project. Questionnaires were sent to the eight faculty heads in each secondary school. The staff were asked to state: (1) their faculty, (2) did they rate their school as urban or rural, (3) was e-conferencing available, (4) would it be useful currently or (5) of future benefit, (6) would the CfE benefit from e-conferencing and finally (7) would access to e-conferencing help develop the CfE in their school. Modified questionnaires which were specific to six subject areas were posted to each headmaster/mistress in all primary schools in Angus. A linear analogue scale of 1-5 was used to determine the extent of benefit staff and pupils would derive for each subject area by using e-conferencing with five representing maximum benefit. Eight secondary schools and 55 primary schools were contacted and 119 questionnaires were posted.

A total of 56 responses were received, representing a 36\% response from secondary schools and $62 \%$ response from primaries. For secondary schools, the results are shown below where $i$ s the number of responses to each question. For question $1,20 \%$ of faculties were Science and $20 \%$ Language, all other six faculties were represented by $10 \%$ of the responses. For question 2, $60 \%$ of staff stated the school was urban.

\begin{tabular}{lrrrrr}
\multicolumn{7}{c}{ Secondary schools responses } \\
\hline Question & 3 & 4 & 5 & 6 & 7 \\
Answer yes $(n)$ & 22 & 18 & 22 & 23 & 20 \\
Answer no $(n)$ & 1 & 4 & 1 & 0 & 3 \\
\hline
\end{tabular}

For primary schools, the average score for each of the six subject areas for pupils and staff were Science 3.40; Environmental studies 3.80; English 3.88; Maths 3.14; Modern Languages 3.91; Expressive Arts 3.30. In conclusion, both primary and secondary school staff felt that access to e-conferencing would benefit their development of the CfE and consequently Health and Wellbeing within their school. E-conferencing may be an important tool for promoting Health and Wellbeing in schools.

1. Cummings JH \& Bingham SA (1998) Br Med J 317, 1636-1640.

2. Expert Panel on School Meals (2003) Hungry for success - A whole school approach to school meals in Scotland. http://www.scotland.gov.uk/library5/ education/hfs-00.asp

3. Curriculum for Excellence (2007) Relevant, inspiring, engaging education for every child and young person in Scotland. http://www.ltscotland.org.uk/ curriculumforexcellence/index.asp 